\title{
Frequency of fragmented QRS in patients with acute Non ST elevation Myocardial Infarction (NSTEMI).
}

\footnotetext{
1. MBBS, FCPS

Assistant Professor Cardiology

Faisalabad Institute of Cardiology, Faisalabad.

2. MBBS, FCPS Cardiology

$P G$ Trainee

Faisalabad Institute of Cardiology, Faisalabad.

3. MBBS, FCPS

Assistant Professor Cardiology

Faisalabad Institute of Cardiology, Faisalabad.

4. MBBS, FCPS

Assistant Professor Cardiology

Faisalabad Institute of Cardiology,

Faisalabad.

5. FCPS (Med), FCPS (Cord)

Associate Professor Cardiology Faisalabad Institute of Cardiology,

Faisalabad.
}

Correspondence Address:

Dr. Muhammad Yasir

Assistant professor Cardiology

Faisalabad Institute of Cardiology,

Faisalabad.

yacir15@hotmail.com

Article received on:

09/09/2020

Accepted for publication:

$10 / 11 / 2020$

\section{Muhammad Yasir ${ }^{1}$, Muhammad Usman ${ }^{2}$, Munir Ahmed ${ }^{3}$, Rehan Riaz ${ }^{4}$, M Hamid Saeed ${ }^{5}$}

ABSTRACT... Objective: To determine the frequency of fragmented QRS complex in patients with acute non-ST elevation myocardial infarction (NSTEMI). Study Design: Cross-Sectional Study. Setting: Department of Cardiology, Faisalabad Institute of Cardiology, Faisalabad. Period: July 15, 2019 to January 15, 2020. Material \& Methods: One hundred and forty five diagnosed patients of NSTEMI on the basis of chest pain and positive troponin-I were included in this study. The electrocardiography (ECG) was performed to document the presence or absence of $f$ QRS complex in these patients. A 12-lead ECG with paper speed of 25 or 50 $\mathrm{mm}$ per second and a voltage of $10 \mathrm{~mm} / \mathrm{mv}$ was used. FQRS was labeled (as per operational definition). The collected data were entered and analyzed statistically by using SPSS v25.0. Data were stratified for age, gender, diabetes, smoking and hypertension. Post-stratification, $f$ QRS complex was compared by Chi-Square test in stratified groups. A p-value $\leq 0.05$ was taken as significant. Results: Total 145 patients presenting with NSTEMI were selected for this study. Mean age of the patients was 48.2 12.3 year. Among these patients, $90(62.1 \%)$ were males, while 55(37.9\%) were females. Overall frequency of fQRS complex in patients with NSTEMI was 64(44.1\%). Conclusion: There is an association of fQRS among patients with acute non-ST elevation myocardial infarction (NSTEMI). Further prospective studies are needed to determine the clinical significance of fQRS complex and identify its correlation with the incidence of possible complications.

Key words: $\quad$ Fragmented QRS Complex, Non-ST Elevation Myocardial Infarction.

Article Citation: Yasir M, Usman M, Ahmed M, Riaz R, Saeed H. Frequency of fragmented QRS in patients with acute Non ST elevation Myocardial Infarction. Professional Med J 2021; 28(1):60-65.

https://doi.org/10.29309/TPMJ/2021.28.01.6185

\section{INTRODUCTION}

Acute coronary syndrome (ACS) is a frequent reason of hospital admission and mortality worldwide. ACS is a spectrum of ST segment elevation MI (STEMI), non-ST segment elevation MI (NSTEMI) and crescendo angina. ECG is the initial investigation in the diagnosis of ACS. In the absence of ST segment elevation, raised cardiac biomarkers differentiate NSTEMI from unstable angina. ${ }^{1}$ NSTEMI results from acute atheromatous plaque change in coronary arteries resulting in subtotal or near complete occlusion of coronary artery and necrosis of myocardium which result in the raised cardiac biomarkers i.e. troponin.

Unlike STEMI with poor short term prognosis, NSTEMI is associated with poor long term prognosis. ${ }^{2}$ ECG can be normal or may show grave changes (i.e. temporary ST segment elevation or ST segment depression and T wave inversion), so raised serum cardiac biomarkers (i.e. troponin) help us to diagnose NSTEMI.

Electrocardiogram (ECG) is an easily accessible, non-invasive and cheap tool used by doctors working in emergency department for diagnosis of ACS. ECG is not only used for the diagnosis but also for prognostic stratification of ACS patients. Anything that can be predicted on ECG is much helpful for immediate and timely management decisions.

Fragmented QRS (f QRS) is a new concept. It means an additional spike in QRS complexes detected on ECG. It is a new and novel marker of cardiac ischemia and fibrosis due to disturbed 
conduction during myocardial infarction and ischemia. Studies have shown the relation between increased rate of ventricular arrhythmias and mortality in acute coronary syndrome with fragmented QRS in ECG as compared to those patients who have no fragmented QRS. ${ }^{3}$

Studies have also revealed that the frequency of poor cardiac, vascular outcomes and recurrent angina are much greater in patients with fragmented QRS in ACS. ${ }^{2}$ Worldwide Studies showed the variable results about the frequency of fragmented QRS in NSTEMI group of patient and results from studies in term of frequency of $f$ QRS in NSTEMI patients were different.

One study by Eyuboglu M showed the frequency of $f$ QRS as $23.5 \%{ }^{4}$ in NSTEMI patients versus another study by Min Li showing the frequency of $55.56 \% .^{2}$ But no published study available in local setting to tell us about the prevalence of this finding in our local population.

\section{OBJECTIVE}

To determine the frequency of fragmented QRS (f QRS) complex in patients presented with acute non-ST elevation myocardial infarction (NSTEMI) in emergency department.

\section{OPERATIONAL DEFINITIONS}

\section{NSTEMI}

It was labeled if the presence of chest pain of cardiac origin for more than $20 \mathrm{~min}$, with troponin $>100 \mathrm{IU}$ or $>0.30 \mathrm{ng} / \mathrm{ml}$ after at least 6 hours of onset of symptoms. ${ }^{5}$

\section{Fragmented QRS complex}

F QRS included various morphologies of the QRS ( $<120 \mathrm{~ms}$ ), which included an extra $R$ wave $\left(R^{\prime}\right)$, an indentation in the lowest part of the $R$ wave or of the $S$ wave, or the existence of more than one $\mathrm{R}$ prime (fragmentation) in two neighboring leads, pointing towards a major coronary artery area. $^{6}$

\section{MATERIAL \& METHODS}

The study was conducted at Department of Cardiology, Faisalabad Institute of Cardiology,
Faisalabad. From July 15, 2019 to January 15, 2020. It was Descriptive Cross Sectional Study. Sample size of 145 patients was considered with $95 \%$ confidence level with $7 \%$ margin of error and taking probable percentage of $f$ QRS as $23.5 \%{ }^{4}$ in NSTEMI patients. Non-Probability Consecutive Sampling was used.

\section{Selection Criteria}

- Patients of ages between 18-70 years

- Patients of either gender

- Patients presenting in Faisalabad Institute of Cardiology with NSTEMI (as per operational definition)

\section{Exclusion Criteria}

- Patients presenting with STEMI

- Patient with typical bundle branch block with QRS > 120 msec

- Patients with valvular or structural heart disease (on medical record)

- Patients with renal failure (creatinine $>1.2 \mathrm{mg} /$ dl), (on medical record)

- Patients with deranged liver function tests (AST>40IU/dl, ALT>40IU/dl, bilirubin > $1 \mathrm{mg} / \mathrm{dl}$ ), (on medical record)

- Patients with Sepsis, muscle injury or trauma (on medical record)

One hundred and forty five diagnosed patients of NSTEMI on basis of chest pain and positive troponin-I were included in this study from the ER Department of Cardiology,

Faisalabad Institute of Cardiology, Faisalabad. Before data collection, Informed consent was taken from all the selected patients.

Patient's name, age, gender, duration of symptoms, history of smoking, diabetes and hypertension were documented in proforma. Then the electrocardiography (ECG) was performed to document the existence or nonexistence of fragmented QRS complex in these patients.

A 12-lead ECG with paper speed of $25-50 \mathrm{~mm} / \mathrm{sec}$ and a current voltage of $10 \mathrm{~mm} / \mathrm{mv}$ was used. ECG analysis were done by two cardiologists. Any disagreement was adjusted by a third reviewer 
(cardiologist).

If any QRS ( $<120 \mathrm{~ms})$, which has an extra $R$ wave $\left(R^{\prime}\right)$ or indentation in the lowest part of the $S$ wave, or $>1 R^{\prime}$ (fragmentation) in 2 neighboring leads, f QRS was labelled (as per operational definition). The collected data were documented in proforma.

The collected data were entered and analysed statistically by using SPSS v25.0. Quantitative variables like age and symptoms time period were presented in the form of mean and standard deviation (SD). Qualitative variables like gender, diabetes, hypertension, smoking and $f$ QRS complex were presented in the form of frequency and percentage. Data were stratified for age, gender, diabetes, smoking and hypertension. Post-stratification, f QRS complex was compared by Chi-Square test in stratified groups. A p-value $\leq 0.05$ was considered to be of significant value.

\section{RESULTS}

Total 145 patients presenting with NSTEMI were selected for this study. Mean age of the patients was 48.2 \pm 12.3 year. Among these patients, $90(62.1 \%)$ were males, while $55(37.9 \%)$ were females.

Majority of the patients $84(57.9 \%)$ had ages between $>45$ years. While $13(9.0 \%)$ and $48(33.1 \%)$ patients were between $18-30$ years and $31-45$ years of age groups respectively.

In this study, $74(51.0 \%)$ patients were hypertensive and $81(55.9 \%)$ as diabetic. Among NSTEMI patients, 33(22.8\%) were smokers.

Overall frequency of fQRS complex in patients with NSTEMI was $64(44.1 \%)$. By stratification of fQRS complex, it was concluded that, there is a significant relationship between fQRS complex and hypertension, smoking and type II diabetes mellitus $(p=0.000001, p=0.030, p=0.000001)$.

\begin{tabular}{|l|c|}
\hline \multicolumn{1}{|c|}{ Gender } & N (\%) \\
\hline Male & $90(62.1 \%)$ \\
\hline Female & $55(37.9 \%)$ \\
\hline Total & $145(100.0 \%)$ \\
\hline
\end{tabular}

Table-I. Frequency distribution of gender.

\begin{tabular}{|c|c|}
\hline Age groups & N (\%) \\
\hline $18-30$ years & $13(9.0 \%)$ \\
\hline $31-45$ years & $48(33.1 \%)$ \\
\hline$>45$ years & $84(57.9 \%)$ \\
\hline Total & $145(100.0 \%)$ \\
\hline \multicolumn{2}{|c|}{ Table-II. Frequency distribution of age groups } \\
\hline Smoking & $\mathbf{N}(\%)$ \\
\hline Yes & $33(22.8 \%)$ \\
\hline No & $112(77.2 \%)$ \\
\hline Total & $145(100.0 \%)$ \\
\hline \multicolumn{2}{|c|}{ Table-III. Frequency distribution of smoking } \\
\hline Diabetes Mellitus & $\mathbf{N}(\%)$ \\
\hline Yes & $81(55.9 \%)$ \\
\hline No & $64(44.1 \%)$ \\
\hline Total & $145(100.0 \%)$ \\
\hline
\end{tabular}

Table-IV. Frequency distribution of diabetes mellitus.

\begin{tabular}{|l|c|}
\hline \multicolumn{1}{|c|}{ Hypertension } & N (\%) \\
\hline Yes & $74(51.0 \%)$ \\
\hline No & $71(49.0 \%)$ \\
\hline Total & $145(100.0 \%)$ \\
\hline \multicolumn{2}{|c|}{ Table-V. Frequency distribution of hypertension. } \\
\hline \multicolumn{2}{|c|}{ fQRS Complex } \\
\hline Present
\end{tabular}

Table-VI. Frequency distribution of FQRS complex.

\begin{tabular}{|l|c|c|c|c|}
\hline \multirow{2}{*}{ Gender } & \multicolumn{2}{|c|}{ FQRS Complex } & Total & P-Value \\
\hline & Present & Absent & & \\
\cline { 1 - 3 } & $39(43.3 \%)$ & $51(56.7 \%)$ & $90(100.0 \%)$ & \multirow{2}{*}{0.803} \\
\hline Female & $25(45.5 \%)$ & $30(54.5 \%)$ & $55(100.0 \%)$ & \\
\hline Total & $64(44.1 \%)$ & $81(55.9 \%)$ & $145(100.0 \%)$ & \\
\cline { 1 - 2 } & & &
\end{tabular}

Table-VII. Stratification of fQRS complex with respect to gender.

\begin{tabular}{|l|c|c|c|c|}
\hline \multirow{2}{*}{ Age Groups } & \multicolumn{2}{|c|}{ FQRS Complex } & \multirow{2}{*}{ Total } & $\begin{array}{c}\text { P- } \\
\text { Value }\end{array}$ \\
\cline { 1 - 4 } Present & Absent & & \\
\hline 18-30 years & $3(23.1 \%)$ & $10(76.9 \%)$ & $13(100.0 \%)$ & \\
\hline 31-45 years & $22(45.8 \%)$ & $26(54.2 \%)$ & $48(100.0 \%)$ & \multirow{2}{*}{0.276} \\
\hline$>45$ years & $39(46.4 \%)$ & $45(53.6 \%)$ & $84(100.0 \%)$ & \\
\hline Total & $64(44.1 \%)$ & $81(55.9 \%)$ & $\begin{array}{c}145 \\
(100.0 \%)\end{array}$ & \\
\hline
\end{tabular}

Table-VIII. Stratification of FQRS complex with respect to age. 


\begin{tabular}{|c|c|c|c|c|}
\hline \multirow{2}{*}{ Smoking } & \multicolumn{2}{|c|}{ FQRS Complex } & \multirow{2}{*}{ Total } & \multirow{2}{*}{$\begin{array}{c}\text { P- } \\
\text { Value }\end{array}$} \\
\hline & Present & Absent & & \\
\hline Yes & $20(60.6 \%)$ & 13 (39.4\%) & $33(100.0 \%)$ & \multirow{3}{*}{0.030} \\
\hline No & 44 (39.3\%) & $68(60.7 \%)$ & $112(100.0 \%)$ & \\
\hline Total & 64 (44.1\%) & 81 (55.9\%) & 145 (100.0\%) & \\
\hline \multicolumn{5}{|c|}{$\begin{array}{l}\text { Table-IX. Stratification of fQRS complex with respect to } \\
\text { smoking. }\end{array}$} \\
\hline \multirow{2}{*}{$\begin{array}{l}\text { Diabetes } \\
\text { Mellitus }\end{array}$} & \multicolumn{2}{|c|}{ FQRS Complex } & \multirow{2}{*}{ Total } & \multirow{2}{*}{ P-Value } \\
\hline & Present & Absent & & \\
\hline Yes & $51(63.0 \%)$ & 30 (37.0\%) & $81(100.0 \%)$ & \multirow{3}{*}{0.000001} \\
\hline No & $13(20.3 \%)$ & $51(79.7 \%)$ & 64 (100.0\%) & \\
\hline Total & 64 (44.1\%) & 81 (55.9\%) & 145 (100.0\%) & \\
\hline \multicolumn{5}{|c|}{$\begin{array}{l}\text { Table-X. Stratification of FQRS complex with respect to } \\
\text { diabetes mellitus. }\end{array}$} \\
\hline \multirow{2}{*}{$\begin{array}{l}\text { Hyper- } \\
\text { tension }\end{array}$} & \multicolumn{2}{|c|}{ FQRS Complex } & \multirow{2}{*}{ Total } & \multirow{2}{*}{ P-Value } \\
\hline & Present & Absent & & \\
\hline Yes & 47 (63.5\%) & 27 (36.5\%) & 74 (100.0\%) & \multirow{3}{*}{0.000001} \\
\hline No & 17 (23.9\%) & $54(76.1 \%)$ & 71 (100.0\%) & \\
\hline Total & $64(44.1 \%)$ & 81 (55.9\%) & 145 (100.0\%) & \\
\hline
\end{tabular}

\section{DISCUSSION}

QRS complex (representation of ventricular depolarization) and ST-T wave (ventricular repolarization) changes are easily and quickly accessible on the ECG which is cheap and readily available tool everywhere). In this way any changes in the Electrocardiogram can be picked and managed early. ${ }^{7-8}$

Presence of subtle abnormality within the QRS complex is associated with myocardial scarring, ischemia and fibrosis which is due to the signal conduction disturbance and ventricular depolarization abnormalities. ${ }^{9}$

When assessing results, fQRS was linked with higher risk of death due to any cause after correction for age, ejection fraction (EF) and presence of type II diabetes mellitus. ${ }^{10}$

Fragmentation results from damaged cells close to an infarcted area where ventricular activation is slow and lacks synchrony leading to RSR' shape of the QRS in 12-lead Electrocardiography. ${ }^{11}$
In a cohort of 56 patients, fragmented QRS appears to have relationship with chronic total coronary occlusion with poor retrograde supply from collaterals in patients who did not have history of myocardial infarction in the past. ${ }^{12}$

Das et al., ${ }^{9}$ showed that wide QRS is linked with a significantly more chances of death when measured with normal QRS $(P=0.017)$ when these patients were followed for 29 months. The study outcomes are in coherence with the death rates published in patients with a fragmented QRS of $<120$ ms duration. ${ }^{13}$

The incidence of ST elevation myocardial infarction has decreased from $66.6 \%$ to $37.5 \%$, and the incidence of NSTEMI has increased considerably. ${ }^{14}$

The changed pattern of ventricular depolarization, most likely represents fragmentation in the QRS complex on ECG. ${ }^{15}$

fQRS has shown relationship for death due to cardiac causes and admission in hospital with heart failure in patients who suffered $\mathrm{MI}$ in the past. ${ }^{16}$

Among the 145 patients who had NSTEMI, 62.1\% were male whereas $37.9 \%$ were females. The patients of fQRS group in the present study had a higher mean age as compared with non-fQRS, but this was not statically significant $(0.276)$.

However, Cetin et al., ${ }^{17}$ Guoet al., ${ }^{7}$ and Dabbagh Kakhkiet al., ${ }^{18}$ showed in their study that age has significant relationship with fQRS. Because of this difference age may not be an important factor. The fQRS was found in $44.1 \%$ patients.

In other studies, like Guoet al. ${ }^{7}$ fQRS was $54 \%$ whereas in another study by Li etal. ${ }^{2}$ fQRS was $46 \%$ and this is almost similar to our study. fQRS complex indicates scar formation of the myocardium, but if somebody has angina it is a sign of ongoing ischemia and alive myocardium which should be treated with early invasive approach to avoid damage to left ventricular function. 
The fragmented QRS complex whether narrow or wide QRS complex is a common finding recorded in an ECG. Studies done in the past have shown that the fQRS is an important indicator of bad cardiac and vascular outcomes, death and heart failure. ${ }^{3}$

The fQRS complex is seen more commonly in those patients who have dilatation of both ventricles and history of infarction. Also if an ischemic heart disease patient has fQRS in ECG he is less likely to have successful reperfusion. ${ }^{4}$

fQRS complexes are a new ECG indicator, which shows delay in conduction of electrical current in coronary artery disease patients. ${ }^{2-19}$ One study found that $23.5 \%$ cases of NSTEMI patients had $f$ QRS. $^{3}$ But another study revealed that fQRS complex was seen in $66.5 \%$ cases of NSTEMI. ${ }^{4}$

HTN and DM were important risk factors in both groups and this resembles with the study by $\mathrm{Li}$ et al. ${ }^{2}$ The findings by Guoetal. ${ }^{7}$ and Dabbagh Kakhkiet al. ${ }^{18}$ are in contrast with ours have no significant diabetic patients in the fQRS group.

The cardiac biomarkers were elevated in the fQRS group which indicates the ongoing ischemia and was significant, similar to the Çetinet al. ${ }^{17}$ In Guoet al. ${ }^{7}$ study, troponin T-value is not significant $(P=$ 0.049 ), which was in contrast with our results. The explanation of this is the presence of chest pain in our study, which was not present in previous studies.

\section{CONCLUSION}

There is an association of fQRS among patients with acute non-ST elevation myocardial infarction (NSTEMI). Further prospective studies are needed to determine the clinical significance of fQRS complex and identify its correlation with the incidence of possible complications.

Copyright@ 10 Nov, 2020.

\section{REFERENCES}

1. Bozbeyoğlu E, Yıldırımtürk Ö, Yazıcı S, Ceylan U, Erdem $A$, Kaya $A$ et al. Fragmented QRS on mortality in patients with non-st-segment elevation myocardial infarction. Ann Noninvasive Electrocardiol. 2015; 21(4):352-7.
2. Min Li, Wang X, Mi S, Chi Z, Chen Q, Zhao X, et al. Short-term prognosis of fragmented qrs complex in patients with non-st elevated acute myocardial infarction. Chinese Med J. 2016; 129(5):518-22.

3. Bozbeyoğlu E, Yıldırımtürk Ö, Yazıcı S, Ceylan U, Erdem A, Kaya A et al. Fragmented QRS on admission electrocardiography predicts long-term mortality in patients with non-st segment elevation myocardial infarction. 2016; (21):352-7.

4. Eyuboglu M, Ekinci MA, Karakoyun S, Senarslan O, Akdeniz B. Fragmented QRS for risk stratification in patients undergoing first diagnostic coronary angiography. Arquivosbrasileiros de cardiologia 2016; 107(4):299-304.

5. Kushner FG, Hand M, Smith SC Jr, King SB 3rd, Anderson $\mathrm{JL}$, Antman EM, Bailey SR, Bates ER, Blankenship JC, Casey DE Jr, et al: 2009 focused updates: ACC/ AHA guidelines for the management of patients with Elevation myocardial infarction (updating the 2004 guideline and 2007 focused update) and ACC/ AHA/SCAI guidelines on percutaneous coronary intervention (updating the 2005 guideline and 2007 focused update) a report of the American College of Cardiology Foundation/ American Heart Association Task Force on Practice Guidelines. J Am CollCardiol 2009; 54:2205-41.

6. Seong C, Gwag H, Hwang J, Park S, Park K, Kim J et al. Clinical significance of fragmented QRS complexes or $\mathbf{J}$ waves in patients with idiopathic ventricular arrhythmias. PLOS ONE. 2018; 13(4):e0194363.

7. Guo R, Li Y, Xu Y, Tang K, Li W. Significance of fragmented QRS complexes for identifying culprit lesions in patients with non-ST-elevation myocardial infarction: A single center, retrospective analysis of 183 cases. BMC Cardiovasc Disord 2012; 12:44.

8. Cheema A, Khalid A, Wimmer A, Bartone C, Chow T, Spertus JA, et al. Fragmented QRS and mortality risk in patients with left ventricular dysfunction. Circ Arrhythm Electrophysiol 2010; 3:339-44.

9. Das MK, Saha C, E Masry H, Peng J, Dandamudi G, Mahenthiran $\mathrm{J}$, et al. Fragmented qrs on a 12-lead ecg: A predictor of mortality and cardiac events in patients with coronary artery disease. Heart Rhythm. 2007; 4:1385-1392.

10. Das MK, Suradi H, Maskoun W, Michael MA, Shen $\mathrm{C}$, Peng J, et al. Fragmented wide qrs on a 12-lead ecg: A sign of myocardial scar and poor prognosis. Circulation Arrhythmia and electrophysiology. 2008; 1:258-68. 
11. Varriale $P$, ChryssosBE. The rsr' complex not related to right bundle branch block: Diagnostic value as a sign of myocardial infarction scar. Am Heart J. 1992; 123:369-76.

12. Kadi H, Ceyhan K, Koc F, Celik A, Onalan O. Relation between fragmented qrs and collateral circulation in patients with chronic total occlusion without prior myocardial infarction. AnadoluKardiyolDerg. 2011; 11:300-04.

13. Yilmaz H, Gungor B, Kemaloglu T, Sayar N, Erer B, Yilmaz $M$, et al. The presence of fragmented qrs on 12-lead ECG in patients with coronary slow flow. Kardiol Pol. 2014; 72:14-19.

14. Sheng QH, Hsu CC, Li JP, Hong T, Huo Y. Correlation between fragmented qrs and the short-term prognosis of patients with acute myocardial infarction. J Zhejiang UnivSci B. 2014; 15:67-74.

15. Hatala R, Savard P, Tremblay G, Page P, Cardinal R, Molin $\mathrm{F}$, et al. Three distinct patterns of ventricular activation in infarcted human hearts. An intraoperative cardiac mapping study during sinus rhythm. Circulation. 1995; 91:1480-94.
16. Roffi M, Patrono C, Collet JP. 2015 ESC guidelines for the management of acute coronary syndromes in patients presenting without persistent ST-segment elevation: Task force for the management of acute coronary syndromes in patients presenting without persistent ST-Segment Elevation of the European Society of Cardiology (ESC). Eur Heart J. 2016; $37(3): 267-15$,

17. Çetin M, Kocaman SA, Erdogan T, Canga A, Durakoglugil ME, Satiroglu Ö, etal. The independent relationship of systemic inflammation with fragmentedQRS complexes in patients with acute coronary syndromes. Korean Circ J 2012; 42:449-57.

18. DabbaghKakhki VR, Ayati N, Zakavi SR, Sadeghi R, Tayyebi M, Shariati F. Comparison between fragmented $Q R S$ and $Q$ waves in myocardial scar detection using myocardial perfusion single photon emission computed tomography. Kardiol Pol 2015; 73:437-44.

19. Amsterdam EA, Wenger NK, Brindis RG. 2014 AHA/ ACC guideline for the management of patients with non-ST-elevation acute coronary syndromes: A report of the American College of Cardiology/ American Heart Association Task Force on Practice Guidelines. J Am CollCardiol. 2014; 64(24):139-228.

\begin{tabular}{|c|l|l|l|}
\hline \multicolumn{3}{|c}{ AUTHORSHIP AND CONTRIBUTION DECLARATION } \\
\hline Sr. \# & \multicolumn{1}{|c|}{ Author(s) Full Name } & Contribution to the paper & Author(s) Signature \\
\hline 1 & Muhammad Yasir & Manuscript writing. \\
\hline 2 & Muhammad Usman & Data collection. \\
\hline 3 & Munir Ahmed & Data analysis. \\
\hline 5 & Rehan Riaz & M Hamid Saeed & Proof reading.
\end{tabular}

